\title{
Textos para ensinar física: princípios historiográficos observados na inserção da história da ciência no ensino
}

\author{
Texts for teaching physics: historiographical principles observed \\ in the insertion of the history of science in education
}

Abigail Vital $^{1}$. Andreia Guerra ${ }^{1}$

\begin{abstract}
Resumo: Os professores se veem, muitas vezes, diante do desafio de elaborar seus próprios textos didáticos quando decidem utilizar a História da Ciência no ensino. Com o objetivo de investigar os princípios historiográficos priorizados e o diálogo que professores de Física estabeleceram com os resultados da pesquisa em ensino de Ciências, realizamos uma pesquisa qualitativa a partir da análise de dissertações e produtos educacionais elaborados por concluintes do Mestrado Profissional. Os resultados demonstram o exercício da vigilância epistemológica feito pelos professores ao tentarem preservar em seus textos a identificação dos cientistas envolvidos, os aparatos utilizados e as conclusões obtidas. As simplificações e os constrangimentos provocados pela transposição didática dessas informações expressam a complexidade que permeia a inserção da abordagem histórica no ensino.
\end{abstract}

Palavras-chave: História da ciência. Historiografia. Ensino de física.

\begin{abstract}
Teachers find themselves faced with the challenge of developing their own didactic texts when they decide to use the history of science in the teaching. In order to investigate both historiographic principles prioritized and the dialogues established between the physics teachers and the results of research in science teaching, we conducted a qualitative study based on the analysis of educational products made by graduates of the Professional Masters. The results suggest that an exercise of epistemological surveillance is done by the teachers in trying to preserve in their texts the identification of the scientists involved, the devices used and the conclusions reached. The simplifications and constraints caused by the didactic transposition in this process express the complexity that permeates the inclusion of the historical approach to teaching.
\end{abstract}

Keywords: History of Science. Historiography. Physics teaching.

\footnotetext{
${ }^{1}$ Centro Federal de Educação Tecnológica Celso Suckow da Fonseca (CEFET-RJ), Programa de Pós-Graduação em Ciência, Tecnologia e Educação, Barra do Piraí, RJ, Brasil. E-mail: <abigailvital@yahoo.com.br>
} 


\section{Introdução}

Atualmente, é corrente a ideia de que cabe à educação científica promover o acesso a informações que permitam a reflexão sobre os procedimentos, os desafios e as limitações da ciência (CONCANNON; BROWN; BROWN, 2013). A História da Ciência tem sido indicada como caminho para provocar e fundamentar tal reflexão e fornecer subsídios para discussões de diferentes visões sobre a ciência, revelando como os cientistas desenvolveram teorias e conceitos, as influências que sofreram e os interesses que os motivaram (FORATO; PIETROCOLA; MARTINS, 2011; GUERRA; REIS; BRAGA, 2013; HODSON, 2009; MARTINS, 2006).

No rol dos obstáculos enfrentados por professores que decidem utilizar concretamente a História da Ciência no ensino de conhecimentos científicos, inclui-se a escassez de textos confiáveis e acessíveis que possam ser utilizados como material didático (FORATO, 2009; MARTINS, 2007; MARTINS, 2006). Embora a oferta desses materiais venha crescendo na mesma proporção em que aumenta o interesse dos estudiosos pelo tema, a construção de textos didáticos com enfoque histórico é uma habilidade que deve ser desenvolvida pelos professores, pois a prática docente não se restringe apenas ao espaço de aplicação de saberes (BRITO, 2005). Reconhecendo a importância da autoria docente no processo pedagógico, estamos certos de que a construção de textos didáticos pode promover a mobilização de saberes que possibilitem a necessária articulação entre os aspectos pedagógicos, historiográficos e epistemológicos dessa construção (SAITO; DIAS, 2013). Entretanto, tal autoria requer autonomia para selecionar fontes, organizar e transpor didaticamente o conhecimento científico com o objetivo de tornálo acessível aos alunos e, ao mesmo tempo, proporcionar reflexões sobre a ciência. Cabe ainda destacar que a autoria de textos didáticos por parte dos professores não é uma tarefa simples. No que tange à História da Ciência, Forato, Pietrocola e Martins (2011) lembram que, na produção de textos didáticos a partir de fatos históricos, devemos atentar para os riscos advindos da simplificação da linguagem e da omissão de informações complexas.

Essas considerações chamaram nossa atenção para o processo em que o professor elabora seus próprios textos e os utiliza como material didático. A busca por textos produzidos pelos próprios professores levou-nos à modalidade de pós-graduação denominada Mestrado Profissional (MP), preferencialmente destinada a professores em serviço, em que os alunos/ professores apresentam, junto à dissertação, um produto educacional por eles elaborado. Assim, desenvolvemos uma pesquisa em que foram analisados produtos educacionais que utilizaram textos como recurso de ensino, vinculados a dissertações de MP. Para melhor delimitar nosso universo de pesquisa, selecionamos produtos educacionais com enfoque histórico que estivessem vinculados ao ensino de Física. Nesse caminho, buscamos responder às seguintes questões: que preocupações tiveram os docentes ao efetuarem as pesquisas que resultaram nos textos oferecidos aos alunos? Como tais preocupações dialogaram com os resultados da pesquisa em ensino de Ciências? Que critérios e cuidados foram priorizados com vistas a não oferecer aos alunos uma visão distorcida e parcial da ciência?

Para responder a essas questões, abordamos, inicialmente, os aspectos da historiografia e da História da Ciência que, segundo resultados divulgados por estudos e pesquisas recentes, não devem ser negligenciados quando o docente se propõe a elaborar textos e outros materiais didáticos que utilizem a abordagem histórica. A seguir, serão descritos os procedimentos metodológicos utilizados e a discussão dos resultados obtidos a partir da análise dos materiais 
Textos para ensinar física: princípios historiográficos ...

nos quais os professores descreveram o processo de elaboração, aplicação e avaliação de textos com abordagem histórica.

\section{A historiografia e a inserção da História da ciência no ensino}

Os historiadores da ciência, ao desenvolverem seus estudos e pesquisas, abordam aspectos referentes à ciência recente e estudos etnográficos e etnológicos do trabalho científico desenvolvido em diferentes culturas. Mas nem sempre foi assim. Até o século XX, a História da Ciência, influenciada por ideias positivistas, teve como objetivo narrar experiências de sucesso dos cientistas e enaltecer a ciência eurocêntrica, apresentando-a em uma sequência linear e cumulativa de fatos que priorizavam o estudo das revoluções científicas que ocorreram entre a Idade Média e a Idade Moderna (KRAGH, 2001). A partir da primeira metade século XX, a História da Ciência surge como disciplina acadêmica. O lançamento da revista Isis, em 1912, é citado como marco desse surgimento (CHRISTIE, 1990).

Inicialmente, eram considerados apenas os fatores internos à ciência, sendo a análise do fenômeno histórico voltada exclusivamente para a construção lógica dos conceitos. E Canguilhem (2002, p. 15) acrescenta: "Aqui, por conseguinte, o fato da história das ciências é tratado como um fato da ciência, a partir de uma posição epistemológica que consiste em privilegiar a teoria relativamente ao dado empírico". Sob influência do materialismo histórico, ainda no século XX, surge a abordagem externalista da História da Ciência, que, de maneira oposta à abordagem anterior, mas igualmente reducionista, privilegia fatores externos à ciência, valorizando essencialmente os contextos em que atuam e vivem os cientistas. Portanto, "o externalista vê a história das ciências como uma explicação de um fenômeno cultural por meio do condicionamento do meio cultural global, e a assimila, por conseguinte, a uma sociologia naturalista das instituições" (CANGUILHEM, 2002, p. 15).

Referindo-se a essas duas abordagens da História da Ciência, Martins (2005) afirma a importância de estabelecermos uma relação de complementaridade entre ambas se desejarmos obter uma historiografia completa, ou seja, uma historiografia que contemple simultaneamente os aspectos internos e externos do conhecimento científico. Para investigar fatores científicos de natureza conceitual, referentes a evidências e fatos de natureza científica, a autora propõe que sejam analisadas fontes primárias. As fontes secundárias, segundo a autora, são adequadas à investigação dos fatores de natureza não conceitual, ou seja, os fatores extracientíficos. Ao afirmar que a História da Ciência é um estudo metacientífico que não apenas descreve, mas também explica e discute a contribuição dos cientistas relacionando-a aos contextos em que a produção científica ocorre, a pesquisadora ainda destaca alguns vícios que devem ser evitados por aqueles que se dispõem a reconstruir fatos científicos: evitar abordagens puramente descritivas da História da Ciência; não procurar no passado somente ideias aceitas atualmente, sem levar em conta o contexto da época; não utilizar a História da Ciência ideologicamente enfatizando, para tanto, algumas questões nacionalistas, políticas ou religiosas; não utilizar apenas informações obtidas em fontes secundárias, sem consultar as fontes primárias. Para não correr o risco de apresentar uma visão distorcida de ciência, ela ainda adverte: "É preciso estudar não apenas os vencedores, mas também os derrotados, verificando quais os argumentos que apresentavam contra as novas ideias" (MARTINS, 2005, p. 314). 
Reafirma-se, assim, que a elaboração dos textos e materiais didáticos com enfoques históricos requer uma seleção fundamentada de fontes históricas de modo a apresentar o conhecimento científico e suas condições de produção em uma perspectiva que viabilize um ensino de ciências capaz de estimular o interesse dos alunos. No entanto, observa-se a dificuldade e, em alguns casos, até mesmo a impossibilidade de se encontrar fontes primárias que não tenham sofrido mudanças por ocasião do processo de tradução. As traduções dessas fontes podem conter distorções e omissões que comprometeriam a veracidade dos fatos nelas relatadas, fazendo com que os materiais mais acessíveis aos professores sejam caracterizados como aproximações do texto original (KUHN, 2007; MARTINS, 2005).

Temendo a perpetuação de falsas histórias sobre a ciência, Allchin (2004) igualmente ressalta os perigos que podem advir da pseudo-história da ciência. Segundo ele, ao tirar da ciência a sua natural complexidade e apresentar os cientistas como heróis - enfatizando apenas suas "descobertas" e omitindo seus erros e dificuldades -, promove-se uma falsa visão sobre a Natureza da Ciência. Whitaker (1979a, 1979b), por sua vez, criticou a quase-história, uma abordagem internalista, factual, com forte marca positivista, que suprime dados que possam macular a imagem da ciência, classificada por Martins (2004) como uma historiografia antiga, que não abrangia o cientista e seu contexto histórico.

Essas considerações não devem se constituir em uma imposição aos docentes que adotam a História da Ciência como eixo condutor de seus trabalhos. Porém, essas são questões importantes a serem consideradas na elaboração de seus materiais instrucionais. Ao elaborarem e aplicarem materiais contendo narrativas históricas, os educadores devem atentar para as questões apontadas por Allchin (2004) e Whitaker (1979a, 1979b). Forato, Pietrocola e Martins (2011), Martins (2005) e Matthews (1994) acrescentam a essa lista de problemas historiográficos os cuidados que devem ser tomados para evitar o whiguismo, abordagem que simplifica a história, desconsiderando os contextos em que viveram os cientistas. Martins (2010) lembra que também deve ser evitada uma atitude extremamente oposta a essa, a interpretação prig da história, ou anti-whiggismo, que defende que ignoremos a ciência moderna que não existia no passado.

Martins $(2005$, p. 307) lembra ainda que "não existe uma fórmula mágica ou receita infalível para fazer uma boa pesquisa em História da Ciência". Isso significa que, durante todo o processo de elaboração e desenvolvimento das pesquisas, partindo-se da reflexão sobre a investigação, faz-se o levantamento das fontes, selecionam-se e se analisam os documentos encontrados e se fundamentam as argumentações e conclusões respaldando-se no conhecimento de técnicas de pesquisa apropriadas.

Os docentes que se propõem a serem autores de seus próprios materiais de ensino não devem desconsiderar outro aspecto igualmente relevante: a historiografia da ciência tem sido fortemente influenciada pelas concepções e metodologias de pesquisa utilizadas pelos historiadores. Embora a análise de textos originais e textos produzidos por historiadores da ciência seja indicada como uma estratégia válida para que os alunos tenham informações sobre os contextos em que surgiram os conceitos científicos, é preciso que os professores fiquem atentos para as dificuldades que podem advir das características dessa historiografia. Ela é produzida a partir de diferentes métodos, visões e objetivos. Os produtos historiográficos podem resultar na expressão de interpretações pessoais que podem culminar na criação de mitos sobre a História da Ciência (KRAGH, 2001). Decorre desse fato a necessidade de se proceder a revisões que privilegiem a verificação da confiabilidade das fontes utilizadas, além da identificação das 
possíveis distorções e equívocos presentes nos materiais disponibilizados para o uso no ensino de ciências. Ao produzir materiais sobre História da Ciência, o professor abordará as obras dos cientistas e o contexto onde essas obras foram produzidas, sempre levando em conta que em toda narrativa histórica se encontra embutida uma visão de ciência.

Embora historiadores e educadores estejam de acordo em relação à importância da interface entre a abordagem histórica e o processo educativo, é expressiva a diferença entre a elaboração de material didático por parte dos educadores e a escrita da História da Ciência por parte de historiadores. São objetivos diferentes que direcionam seus trabalhos. O historiador investiga os acontecimentos do passado para resgatar e difundir a memória coletiva e assim promover a compreensão da condição humana em seus aspectos econômicos, sociais e culturais. O professor, por sua vez, mobiliza diferentes saberes para desenvolver ações com objetivos emocionais, sociais, cognitivos e coletivos relacionados aos alunos, à disciplina que leciona, à aprendizagem e ao projeto educacional de sua escola (TARDIF, 2000). Essa diferença ressalta a importância da autoria docente no processo pedagógico e não impede que os professores adotem procedimentos que se aproximem dos princípios que caracterizam a historiografia: independentemente da finalidade do material didático é fundamental que o professor mantenha a integridade do contexto dos sujeitos e fatos históricos e explicite os aspectos referentes à Natureza da Ciência (SAITO; DIAS, 2013).

Buscar a qualidade pedagógica na elaboração de textos para o ensino de ciências implica em termos a possibilidade de estimular os alunos a perceberem lacunas no conhecimento dos cientistas, característica inerente à ciência apresentada como um processo inacabado. Cabe ressaltar que, embora favoreçam a percepção de outros sentidos para os fenômenos científicos, o uso de textos não é determinante na aprendizagem, pois eles são apenas meios didáticos que, dependendo da mediação do professor, podem ou não potencializar a aquisição de competências e habilidades necessárias à aquisição de novos conhecimentos (SALOMON, 2000). Comungando das mesmas ideias, pesquisadores como Krasilchik (2012), Martins (2007) e Martins (2005) recomendam a utilização de materiais que, além de despertar a curiosidade e o interesse dos alunos, destaquem a relevância atribuída aos experimentos históricos em seu contexto de origem superando, assim, uma abordagem meramente factual e descritiva da construção do conhecimento científico.

\section{Caminhos metodológicos}

Recorremos a uma abordagem qualitativa para responder às questões destsa pesquisa. Consideramos, inicialmente, os desafios enfrentados por professores que optaram por utilizar concretamente a História da Ciência como eixo condutor dos conteúdos de Física. Encontramos, no MP em Ensino de Ciências, professores com o perfil adequado à presente investigação. O MP em Ensino de Ciências é uma modalidade de pós-graduação na qual os professores são estimulados a elaborar, aplicar e avaliar produtos educacionais que efetivam a aplicação do conhecimento gerado e adquirido por eles. Quando o produto educacional vinculado à dissertação é aplicado ao longo do mestrado, os resultados da avaliação da aplicação daquele são descritos nas dissertações defendidas ao final do curso.

A partir dessas considerações, realizamos junto ao Portal de Periódicos da Coordenação de Aperfeiçoamento de Pessoal de Nível Superior (CAPES), uma pesquisa os programas de MP 
na área de Ensino, com vistas a destacar aqueles que apresentassem uma linha de pesquisa na área de História da Ciência e Ensino e dissertações vinculadas a tal linha de pesquisa. Com o objetivo de identificar as produções que utilizaram a História da Ciência como eixo condutor do ensino de Física, iniciamos a seleção das dissertações delimitando o período de investigação aos anos 2010 e 2011. Nesse período, ocorreu um recrudescimento da produção e da pesquisa que pode ser constatado pelo número de dissertações defendidas em programas da área. (NARDI, 2015).

Dentro desse recorte temporal, buscamos as dissertações nas quais os professores explicitaram a aplicação do produto educacional. Essa opção se deveu ao fato de a aplicação implicar o contato com a realidade das escolas e permitir a reflexão sobre a ação empreendida, além de caracterizar o docente como sujeito ativo de sua prática, capaz de "[...] transformar a matéria que ensina para que os alunos possam compreendê-la e assimilá-la" (TARDIF, 2002, p. 120). A opção por textos que haviam sido aplicados em sala de aula limitou o universo desta pesquisa, porém permitiu ampliar a análise, uma vez que nos permitiu conjugar a leitura do texto didático produzido pelos professores com a descrição que eles mesmos apresentaram sobre a aplicação dos textos, conforme ficará explícito na análise de resultados.

Como resultado da busca, foram identificados dez trabalhos, sendo: dois da Universidade Estadual da Paraíba (UEPB), um da Universidade Federal do Rio Grande do Norte (UFRN) e sete do Centro Federal de Educação Tecnológica Celso Suckow da Fonseca, do Rio de Janeiro (CEFET-RJ). Vale ressaltar que os programas de pós-graduação das instituições envolvidas na pesquisa apresentam como objetivo aprofundar a formação de docentes dos diversos níveis de ensino de Física, quanto ao domínio de conhecimentos envolvidos no processo de ensino e aprendizagem dessa disciplina, relevando os aspectos epistemológicos, metodológicos e históricos.

Nomeamos as dissertações utilizando uma codificação alfanumérica (D1 a D10), sendo aleatória a ordem a elas designada (Anexo A). Esses trabalhos foram submetidos à análise de conteúdo proposta por Bardin (2011). A escolha desse método de análise de dados, dentre outras possibilidades existentes no campo das pesquisas qualitativas, deve-se à busca por um procedimento que proporcionasse uma visão abrangente sobre as informações disponíveis nos documentos analisados. Um procedimento que permitisse não apenas organizar o conteúdo das dissertações, mas também fazer inferências acerca da elaboração e aplicação dos textos didáticos, nosso foco principal de atenção. À fase em que foram definidas as dissertações que se constituíram em objeto da pesquisa, denominada por Bardin de pré-análise, seguiram-se a leitura flutuante com o propósito de aprofundar o conhecimento sobre as opções dos autores (BARDIN, 2011, p. 126). Orientadas pelas questões que a pesquisa busca responder e pelo objetivo da pesquisa, definimos duas unidades de análise: (A) diálogo entre referencial teórico e objetivos propostos; (B) princípios da historiografia adotados pelos autores do material didático produzido. Definidas as categorias, iniciou-se a organização do material com vistas à compreensão dos significados atribuídos pelos sujeitos da pesquisa, cuja discussão será apresentada a seguir.

\section{Discussões em torno aos resultados obtidos}

Antes de procedermos à análise das categorias selecionadas, é importante destacar que os textos didáticos continham exemplos, analogias, fotografias, mapas, diagramas, elementos 
que, segundo os professores afirmaram no corpo das dissertações, visavam tornar a leitura mais acessível aos alunos. Os textos produzidos pelos docentes se dividiam em dois gêneros textuais distintos: seis professores construíram textos argumentativos, ou seja, textos que apresentavam posicionamento do autor sobre o tema tratado, enquanto quatro docentes apresentaram textos informativos, em que apenas informações sobre o tema foram apresentadas (KAUFMAN; RODRIGUEZ, 1995).

Apresentamos a seguir a análise em que procuramos realçar os sentidos manifestos e latentes que os docentes expressaram sobre o diálogo com a literatura da área e os princípios historiográficos que nortearam a elaboração dos textos.

\section{Categoria A: Diálogo entre literatura e objetivos propostos}

Na categoria A, foram organizados os indicadores relativos à literatura utilizada como referência pelos autores das dissertações na definição dos objetivos propostos para a elaboração e aplicação dos produtos educacionais. Considerando o fato de que a maior parte dos trabalhos analisados é oriunda de uma mesma instituição, é possível inferir que a frequência de bibliografias utilizadas pode ter sido determinada pela formação metodológica oferecida nessa instituição. Cabe, entretanto, destacar que as dissertações dessa instituição foram orientadas por diferentes docentes.

Dentre os vários estudos citados, destaca-se o trabalho de Matthews (1995), publicado originalmente em 1992, em inglês. Os argumentos que o pesquisador australiano utilizou para recomendar o uso da História da Ciência no ensino foram referenciados em todas as dez dissertações e determinaram a formulação dos objetivos propostos pelos docentes. $\mathrm{O}$ tratamento contextual e abrangente proposto por Matthews para a incorporação dos temas da História da Ciência é explicitado no corpo das dissertações e nos produtos educacionais. Dessa forma, todos os autores destacam que a finalidade das propostas desenvolvidas não é a inclusão da História da Ciência como um novo componente curricular, mas promover a discussão e a reflexão sobre os fatos históricos com vistas a produzir discussões sobre a ciência, como vemos nos dois exemplos a seguir.

D5: Nossa proposta pedagógica de inserção da FMC no EM, a partir de uma abordagem histórico-filosófica, não teve como objetivo lançar mão do contexto histórico-filosófico como um enxerto de conteúdo, mas sim como um eixo condutor do trabalho, capaz de contextualizar a construção do conhecimento científico. (MORAIS, 2011, p. 46).

D8: Matthews considera o professor a chave do sucesso para essa inserção [...]. [Essa afirmação] pode ser considerada definitiva para os propósitos desta dissertação que busca examinar uma das possíveis formas - a demanda epistemológica - que possam levar um professor de ciências a passar de um professor apenas observador das potencialidades educacionais que a HFC possui para ser um professor "ativista" dessas potencialidades. (ARCANJO FILHO, 2011, p. 16). 
Importante destacar que os textos apresentados tinham a História da Ciência como eixo condutor, no sentido de apresentar os conteúdos científicos a partir da narrativa histórica desenvolvida. Dessa forma, a História da Ciência não se apresentava como um adendo ao tema a ser trabalhado com os alunos.

Oito das dez dissertações fazem referência ao trabalho do pesquisador Roberto Martins acerca da História da Ciência. Embora a obra desse historiador se refira principalmente aos fundamentos históricos das ciências, fontes e aspectos da pesquisa científica, os professores referiram-se às contribuições que Martins apresenta para a inserção da História da Ciência no ensino. Em particular, as dissertações ressaltam a defesa que Martins faz quanto ao estudo adequado dos episódios históricos como caminho para tal inserção. Esse aspecto é utilizado pelos professores para fundamentar a formulação de objetivos e destacar o cuidado que tiveram ao incorporar a História da Ciência no ensino, conforme é possível observar no exemplo transcrito a seguir.

D3: Estaremos, também, alerta [sic] à advertência de MARTINS (2006) de que o uso da História da Ciência pode ser um obstáculo ao bom ensino. Como por exemplos, reduzir a História da Ciência a nomes, datas e anedotas, de forma a levar o aluno a considerar que as teorias são obtidas a partir de observações, concepções errôneas sobre o método científico e uso de argumentos de autoridade. (MENEZES, 2010, p. 9).

D9: A História da Ciência nos permite discutir o desenvolvimento de teorias e conceitos; a maneira de trabalhar dos cientistas; as ideias rejeitadas hoje que não o eram no passado; o tipo de relação existente entre Ciência, religião e Filosofia e, ainda, que tipo de relação existe entre o desenvolvimento científico e outros desenvolvimentos históricos ocorridos no mesmo período (MARTINS, 2006). (BEZERRA, 2011, p. 9).

A incidência do artigo de Martins (2006) nas dissertações é uma questão a ser problematizada. A maior parte da obra desse autor se refere a pesquisas em História da Ciência. Porém, em 2006, em um momento em que a publicação referente à História da Ciência e ensino já estava consolidada, Martins escreveu um artigo em que defendia o uso da História da Ciência na educação básica, destacando cuidados a serem tomados, como a preocupação com a reflexão sobre o contexto de produção do conhecimento científico, sobre o caráter coletivo e a complexidade da construção da ciência. O fato de Martins (2006) ser tomado como referência em detrimento de outros autores da área de ensino de Física, que antes mesmo de 2006 já justificavam a inserção da História da Ciência no Ensino, sugere que os professores utilizaram a autoridade do autor na área da História da Ciência para ressaltar o reconhecimento que tinham dos problemas oriundos do uso da História da Ciência no ensino. Decorre desse fato que os docentes privilegiaram o diálogo com a historiografia da ciência. Outro ponto que reforça esse argumento é o fato de que, em sete dissertações, nos capítulos em que descrevem o episódio histórico selecionado, os docentes utilizaram obras de Roberto Martins como fonte historiográfica secundária.

A inclusão dos aspectos referentes à Natureza da Ciência nos produtos educacionais, com o objetivo trabalhar com os alunos uma visão não deformada da ciência, tendo por 
referência o artigo de Gil-Pérez et al. (2001) é observada em seis dissertações. Gil-Pérez et al. (2001) afirmam que concepções que apresentam aspectos lineares, cumulativos e apartados do contexto histórico-social contribuem para a propagação de visões inadequadas sobre a ciência. Como exemplo, apresentamos o excerto a seguir:

D4: [...] é possível observar, pela pesquisa de Gil-Pérez et al., (2001) que existe um consenso nas visões distorcidas sobre ciências dos professores. [...] Nesse trabalho, escolhemos três características da natureza da ciência para serem explorados em sala de aula visando desconstruir um modelo pré-existente sobre conhecimento científico. São elas: uma observação não é possível sem ideias pré-existentes; a necessidade de divulgação entre pares para validar o conhecimento adquirido; é sempre possível mais de uma interpretação para o mesmo fenômeno. (MONTEIRO, 2011, p. 24).

As análises da História da Ciência feitas por Kuhn (2007) são citadas em cinco dissertações. Vale destacar que o físico e filósofo estadunidense não defende o uso da História da Ciência no Ensino. Para ele, ao trabalharmos os conteúdos científicos em uma abordagem histórica estaríamos colocando dúvidas para os alunos e, portanto, não estariamos contribuindo para a formação deles no paradigma vigente. Isso, segundo Kuhn, poderia afastar os alunos da carreira científica. Observa-se que três dissertações destacam essa advertência de Kuhn, enquanto duas, mesmo sem fazer referência a esse posicionamento do filósofo, consideram seus argumentos de que os manuais apresentam a História da Ciência apenas de forma ilustrativa, sem destacar a relação entre observação, experimentação e formulação de teorias, conforme exemplos transcritos a seguir.

D4: Para Kuhn a ciência amadurecida retratada nos livros didáticos, que ele denomina manuais, não contempla a relação com o seu contexto histórico e "acaba escondendo o processo que está na raiz dos episódios mais significativos do processo científico". [...] Sendo assim, nesse trabalho utilizaremos [...] episódios sobre a descoberta dos raios X e sobre a descoberta da radioatividade, que apresentam uma história repleta de controvérsias, bem como permite uma aproximação maior do aluno com a história da ciência. A intenção é de problematizar o desenvolvimento histórico da ciência [...] (MONTEIRO, 2011, p. 16; 30).

D5: Após revisão feita através dos slides, achamos pertinente falar da Nathurphilosophie quando mencionamos a busca da construção de uma teoria que explicasse a totalidade dos fenômenos da natureza. Em seguida, abordamos as ideias de Mayer e Joule no que tange à construção do Princípio de Conservação de energia, ilustrando o que Kuhn chama de descoberta simultânea. (MORAIS, 2011, p. 107).

O trabalho de El-Hani (2006), referenciado para a formulação de objetivos em quatro das dez dissertações, apresenta uma proposta contextualizada para o ensino de ciências e 
recomenda a discussão dos aspectos da Natureza da Ciência com vistas à transformação de visões equivocadas da ciência, nos termos exemplificados no excerto a seguir:

D9: [...] buscar novas possibilidades e dimensões para os alunos a respeito do funcionamento interno e externo da Ciência, como o conhecimento cientifico é construído, quais os métodos que a Ciência usa para validar esse conhecimento, resumindo, sobre a natureza da Ciência [...]. (BEZERRA, 2011, p. 24).

Da mesma forma, quatro dissertações consideraram os estudos de Peduzzi (2001) na formulação dos objetivos que dizem respeito à elaboração de material instrucional que não enfatize apenas o produto final da ciência, mas permita a transformação das imagens estereotipadas e estéreis que geralmente são associadas ao conhecimento científico.

D3: Ao trabalhar os textos, pretende-se enfocar obras literárias de épocas históricas distintas, assim como diferentes olhares para a Ciência, especialmente para a Física. Espera-se que esse confronto permita ao aluno perceber que o olhar sobre a Ciência não é estático, sendo afetado pelo contexto sociocultural do autor trabalhado. (MENEZES, 2011, p. 25).

A análise das articulações existentes entre as fontes teóricas utilizadas e os objetivos propostos para o ensino dos conteúdos demonstrou o esforço dos professores que, como autores do processo de incorporação da História da Ciência ao ensino, procuraram dialogar com as ideias e advertências presentes na bibliografia consultada. Nesse sentido, os docentes se propuseram a criar textos com enfoque histórico, reconhecendo os problemas apontados por historiadores da ciência e educadores.

A partir análise dos dados apresentados, é possível inferir que os professores atuaram como sujeitos ativos no processo de ensino-aprendizagem e se respaldaram na literatura da área de ensino de ciências articulando os resultados das pesquisas e os elementos da História da Ciência.

\section{Categoria B: Princípios historiográficos observados}

$\mathrm{Na}$ categoria B, foram organizados os princípios da historiografia explicitados pelos professores tanto na descrição da elaboração da sequência didática em que o texto foi aplicado, quanto os observados nos textos didáticos que foram apresentados aos alunos.

Inicialmente, percebemos a primazia da utilização de fontes primárias por parte dos professores na fundamentação dos produtos educacionais, assim como nos textos por eles elaborados: em sete dissertações, os professores utilizaram, além de fontes primárias, algumas fontes secundárias, enquanto os autores das outras três dissertações utilizaram apenas fontes secundárias. Um dado importante é que apenas três fontes primárias não foram consultadas em língua portuguesa, ou seja, as fontes primárias utilizadas, em grande parte, não são originais, mas traduzidas, conforme se pode observar nas referências das dissertações. No entanto, nenhum professor destacou problemas e dificuldades que poderiam ter advindo da leitura de traduções, 
nem sempre fiéis. Observa-se também que as fontes secundárias foram utilizadas não apenas para investigar fatores contextuais e extracientíficos, mas também fundamentaram a abordagem de questões conceituais. Roberto Martins, o historiador da ciência que em oito dissertações foi referenciado para justificar a inserção de História da Ciência, é marcadamente referenciado na bibliografia indicada pelos professores ao final dos textos didáticos. Observou-se que esse autor foi citado como fonte secundária não para fatores contextuais e sociológicos da ciência, como destaca Martins (2005), mas como fonte historiográfica para a construção histórica dos aspectos conceituais do conhecimento científico.

Importante destacar que a preocupação dos professores com as visões distorcidas e parciais da ciência, manifestada nos objetivos e ricamente discutida nas seções que apresentavam o referencial teórico das dissertações, em alguns momentos, não dialogaram explicitamente com a literatura consultada. Pudemos observar que, sem que os professores manifestassem críticas aos referenciais adotados, em quatro das cinco dissertações em que as recomendações de El-Hani (2006), Gil-Pérez et al. (2001) e Peduzzi (2001) foram citadas para discutir visões adequadas da ciência, verifica-se a produção de textos contendo alusões ao trabalho isolado de filósofos naturais e à genialidade de cientistas.

D2: Pela primeira vez se dispunha de uma teoria que possibilitava a compreensão do sistema solar e de todo o universo. Essa teoria foi publicada por Newton nos "Princípios Matemáticos da Filosofia Natural", em 1687 [...]. (LOURENÇO, 2010, p. 88, grifo do autor).

D3: Contudo, na busca da verdade, para Newton, a Matemática e a Física se apresentavam junto à Alquimia, formando os mecanismos para se conhecer o mundo perfeito. Ele, porém, como um gênio de soberba inteligência, se visse dos nossos dias os avancos da ciência, nos mostraria os mistérios que envolvem a quintessência. Gonçalo Ferreira da Silva, Sir Isaac Newton (2007). (MENEZES, 2010, p. A3-1/A3-2, grifos do autor).

D8: [...] Por que as estrelas, a Lua e o Sol caminham no espaço? A solução para este problema foi dada, pela primeira vez, por outro pensador grego chamado Heráclides do Ponto [...]. (ARCANJO FILHO, 2011, p. 92).

D9: [...] Hesíodo foi considerado como o pai da poesia didática e um inspirador de gerações porque suas obras mantiveram-se por tradição oral, já que na sua época não se conhecia a escrita. (BEZERRA, 2011, p. 61).

Por outro lado, os mesmos textos apresentam evidências do caráter coletivo e humano da ciência, ressaltando controvérsias e as contribuições dos cientistas que, normalmente, não são citados em materiais didáticos disponibilizados aos alunos. Essa aparente incoerência não nos permite caracterizar a incompreensão das fontes utilizadas pelos professores, mas parece demonstrar a complexidade inerente à elaboração de textos dessa natureza e ao processo de transposição didática do conhecimento científico, indicando, ainda, que, mesmo conhecendo as críticas feitas pela literatura da área à visão de genialidade de cientistas e à visão de que os 
cientistas trabalham solitariamente, os professores têm dificuldade em construir textos didáticos sem alusões a pessoas especiais como construtores da ciência.

D2: Com este simples texto percebemos que as interpretações foram adquiridas, enriquecidas e repassadas de geração a geração, ocorreram inicialmente através da observação dos fenômenos naturais e sofreram influência das relações humanas estabelecidas até a formação da sociedade, isso em conformidade com os padrões de comportamentos éticos ou morais tidos como aceitáveis em determinada época por um determinado grupo ou determinada relação humana. (LOURENÇO, 2010, p. 121).

D3: Newton respondeu a esta questão, como será visto mais tarde. No entanto, os trabalhos de outros pesquisadores contribuíram para formular a resposta. Copérnico (1493-1543), Tycho Brahe (1546-1601), Kepler (15711630) e Galileu (1564-1642) foram alguns que influenciaram os estudos de Newton. A grande preocupação dos filósofos naturais era explicar os movimentos no céu e na Terra, de modo semelhante. [...] (MENEZES, 2010, p. A2-4).

D8: [...] muitos historiadores defendem a ideia de que a ciência, como a entendemos atualmente, começou com os gregos na antiga Jônia. É claro que antes dos gregos, como já dissemos, outras pessoas já pensavam sobre as coisas do universo e do mundo. (ARCANJO FILHO, 2011, p. 80).

D9: Não muito satisfeitos com as explicações de Empédocles levantam-se os atomistas, inicialmente na figura de Leucipo, e, posteriormente, na figura de maior relevância, de Demócrito.

É interessante notar que a ideia atomista aparece entre meados e o final do século $\mathrm{V}$ a.C., mas o que conhecemos atualmente como teoria atômica remonta ao século XIX. É bem verdade que o átomo do século V a.C. é diferente daquele que temos hoje, mas é importante entender que essa ideia fora levantada há muito tempo. (BEZERRA, 2011, p. 74).

Com exceção do texto apresentado na dissertação D4, os demais apresentaram os temas sem fazer um recorte histórico de uma época. Essa opção pode fazer com que os riscos provocados pelas simplificações sejam maiores e ocorram em maior escala do que quando a opção é feita por recortes temporais da história (MARTINS, 2005).

Em uma das dissertações, percebemos textos que podem induzir a uma ideia de continuidade e linearidade do desenvolvimento do conhecimento científico:

D9: Os dois princípios de conservação citados nesse texto [...] constituem os pilares da física, e a quantidade de problemas que eles resolvem é enorme. Suas formulações, que são bastante atuais, vieram de discussões feitas lá atrás pelos filósofos pré-socráticos. (BEZERRA, 2011, p. 78). 
Embora a apresentação exclusiva de correntes vitoriosas da ciência tenha dado lugar a abordagens que relacionaram a contribuição dos cientistas aos contextos em que se situavam, ainda ocorreram algumas distorções, cujos prejuízos foram reconhecidos pelos próprios professores.

D4: Na preocupação em elaborar um texto curto, em linguagem acessível e prazerosa para os alunos, acabamos por incorrer em erros consideráveis [...] uma excessiva simplificação pode acarretar um grande risco em termos de distorção histórica, podendo gerar narrativas históricas muito superficiais, destacando ainda, que simplificação e omissão é um desafio a enfrentar. (MONTEIRO, 2011, p. 70).

D7: A última dificuldade que merece nossa atenção é relativa à utilização da História da Ciência no ensino. Primeiramente, é preciso ter muito cuidado com as fontes de consulta, para que os fatos não sejam distorcidos. Assim, é importante que se leia mais de um autor sobre o mesmo assunto, para que se possa verificar possíveis erros. Também pela falta de experiência do professor regente [...], foi necessário realizar muitas leituras a respeito do tema abordado com os alunos. [...] (PEREIRA, 2011, p. 55).

Observa-se que as questões exemplificadas representam as tentativas feitas pelos professores para transformar os fatos e fenômenos históricos em objetos ensináveis. Para que esses objetivos fossem alcançados, o conhecimento histórico-científico veiculado por meio dos textos sofreu transformações transpositivas (CHEVALLARD, 1991). A análise cuidadosa desse processo de didatização dos extratos históricos possibilita a identificação de alguns indícios da transposição didática e dos cuidados observados pelos autores das dissertações para evitar a perpetuação das distorções da ciência. No trecho a seguir, verifica-se que a descontextualização histórica fica evidente quando os fatores que motivaram e deram sentido aos estudos sobre Óptica foram omitidos:

D1: [...] Depois da queda do Império Romano, os estudiosos árabes aperfeiçoaram os seus estudos sobre Óptica, exercendo influência significativa sobre os estudiosos de óptica da Idade Média. (SILVA, 2010, p. 100).

Em outro exemplo, observa-se a inexistência de referências a outros personagens da época como William de Sitter, estudioso da mesma temática (ASSIS; NEVES; SOARES, 2009). A omissão a respeito de debates e controvérsias retira do empreendimento científico o seu caráter social e ressalta a genialidade, caracterizando a ciência unicamente como resultado de esforços e dons pessoais.

D10: Mas como surgiu essa ideia de que o Universo teve um começo? Essa cosmologia surgiu através dos resultados das equações da relatividade apresentadas por Albert Einstein no início do século XX. 
Einstein provocou uma revolução na forma de se ver o cosmo quando desenvolveu sua relatividade restrita para a geral. [...] (GUTTMANN, 2011, p. 17).

Por outro lado, no trecho a seguir, observa-se o cuidado do autor ao narrar os fatos históricos, evitando o empobrecimento da informação, muito comum na maioria dos livros didáticos, nos quais, em geral, a "descoberta" da força da gravidade é exclusivamente atribuída a Newton:

\begin{abstract}
D3: [...] E na Terra, é verdade que as pedras caem por causa da força da gravidade? A mesma causa (força da gravidade) tem efeitos diferentes? Newton respondeu a esta questão, como será visto mais tarde. No entanto, os trabalhos de outros pesquisadores contribuíram para formular a resposta. Copérnico (1493-1543), Tycho Brahe (1546-1601), Kepler (1571-1630) e Galileu (1564-1642) foram alguns que influenciaram os estudos de Newton. [...] (MENEZES, 2010, p. A2-4).
\end{abstract}

De maneira geral, constata-se, na análise dos dados agrupados nessa categoria, o exercício da vigilância epistemológica feito pelos professores ao usarem fontes primárias na elaboração dos textos didáticos e recorrerem a fontes secundárias de autores reconhecidos pela comunidade científica. As simplificações e os constrangimentos provocados pela transposição didática das discussões históricas, que se materializam de alguma forma nos produtos finais, expressam, na verdade, a complexidade que permeia a inserção da História da Ciência no ensino e não devem desmerecer a importância conferida pelos professores à elaboração e à aplicação de materiais instrucionais adequados ao ensino do conhecimento científico.

\title{
Considerações finais
}

Este estudo, sem a pretensão de se tornar conclusivo, procedeu à análise dos textos históricos educacionais elaborados por concluintes do MP e descritos em suas dissertações. A análise pretendeu responder às perguntas: que preocupações tiveram os docentes ao efetuar as pesquisas que resultaram nos textos oferecidos aos alunos? Como tais preocupações dialogaram com os resultados da pesquisa em ensino de ciências? Que critérios e cuidados foram priorizados com vistas a não oferecer aos alunos uma visão distorcida e parcial da ciência? Para responder a tais questões, foram, então, geradas e sistematizadas categorias que possibilitaram a interpretação das escolhas feitas pelos docentes, atestando a importância da autonomia e autoria docente. Permitiu, ainda, a identificação da validade das propostas, o reconhecimento do esforço de seus autores e a importância desses estudos para o ensino da Física.

A análise do material selecionado como objeto desta pesquisa possibilitou apontar que, sensibilizados e desafiados pela necessidade de buscar respostas para solucionar os problemas enfrentados no dia a dia das salas de aula, os concluintes dos cursos de Mestrado Profissional no Ensino de Ciências, cujas dissertações foram analisadas neste artigo, tiveram a preocupação de elaborar, aplicar e avaliar textos que permitissem práticas consideradas por eles inovadoras 
para o ensino da Física. Apoiando-se em estudos da área de ensino de Ciências, os docentes procuraram produzir materiais que trouxessem às aulas discussões sobre a Ciência, com vistas a ultrapassar visões distorcidas sobre ela.

O desinteresse dos alunos em relação ao estudo da Física foi outro elemento motivador para a inserção da História da Ciência no ensino, conforme revela a leitura das dissertações. Como resultado dessa inserção, os professores destacaram em nove dissertações que observaram uma expressiva participação dos alunos nas aulas, nos debates e nas atividades propostas em sala de aula.

O papel de destaque conferido pelos docentes à participação e ao interesse dos alunos na aplicação dos produtos educacionais e o papel ativo assumido pelos professores na elaboração de materiais instrucionais levam-nos a concluir que a forma como a História da Ciência foi incorporada aos produtos educacionais analisados é o elemento inovador, para o qual cabe destaque. Apresentados como eixo condutor dos conteúdos de Física, os aspectos históricos contidos nos textos não representaram meros adornos ilustrativos ou anedotas sobre gênios e seus feitos maravilhosos. Esses aspectos também não se constituíram em um acréscimo de conteúdo extra à disciplina. Por outro lado, enfrentando obstáculos para a construção de um material didático próprio, os docentes não apresentaram uma escrita estritamente respaldada nas pesquisas: em alguns textos, como destacado anteriormente, os professores oscilaram entre apresentar a ciência como um trabalho coletivo e atribuir a uma pessoa isolada a autoria de uma teoria. Porém, atuaram como autores, demonstrando o conhecimento adquirido em sua formação, quando atentaram para as tendências historiográficas atuais divulgadas no domínio da inserção da História da Ciência no ensino.

Outro aspecto importante a ser observado se refere à formação docente. A participação efetiva dos docentes no processo de elaboração de materiais didáticos com abordagem histórica é influenciada pela realidade observada nos cursos destinados à sua formação (HOTTECKE; SILVA, 2011; MARTINS, 2007). As licenciaturas vêm incorporando cursos de História da Ciência aos seus currículos, buscando garantir a desenvoltura esperada na atuação dos docentes. Como adverte Gução et al. (2011, p. 264): “Se o professor não tiver uma formação sólida em História da Ciência, talvez caia em uma reprodução daquilo que é veiculado pelo material escolhido, o que pode ser desastroso para o ensino". Porém, é importante destacar a importância de se problematizar, junto aos professores em exercício e futuros professores, que um conhecimento sólido de História da Ciência não basta quando se propõe a enfrentar o desafio de produzir práticas pedagógicas e elaborar materiais adequados ao trabalho em sala de aula. $\mathrm{O}$ uso da História da Ciência no ensino requer ainda que os docentes assumam uma postura dialógica que os habilite a se familiarizar com aspectos culturais que envolvem as expectativas dos alunos em relação ao conteúdo da Física (HOTTECKE; SILVA, 2011).

Não foram mencionadas nas dissertações referências que representassem o aporte teórico para a dimensão didática dos produtos educacionais. Sem mencionar tais referências, os professores não explicitam os fundamentos metodológicos adotados para respaldar a utilização dos textos na sala de aula, porém, podemos inferir, a partir da análise dos textos, que os docentes buscaram formas diferenciadas de construir seu material didático. É possível constatar que eles se valeram do saber profissional adquirido ao longo de suas carreiras, revelando em diferentes momentos das dissertações seu compromisso com um ensino voltado às necessidades fundamentais do alunado. 
Os resultados desta pesquisa apontam, ainda, para a importância do reconhecimento dos professores como profissionais capazes de construir sua própria prática. As dificuldades evidenciadas, ao contrário de apontarem para a necessidade de especialistas construindo o material didático, sugerem que os docentes, como conhecedores de seu espaço de trabalho, são aptos a produzir práticas pedagógicas e materiais didáticos. Os sujeitos desta pesquisa não aplicaram um material previamente disponibilizado por agentes externos, sugerindo que buscaram produzir uma solução, agindo como protagonistas do desenvolvimento de possibilidades educativas.

Esta pesquisa representa a primeira etapa de uma investigação em andamento cujo objetivo é realizar estudos mais aprofundados sobre a utilização da História da Ciência como eixo condutor do ensino de Física. Os desafios enfrentados e as alternativas de solução propostas em face do cotidiano das práticas educativas continuam a provocar inquietações nas autoras.

\section{Agradecimentos}

Ao Conselho Nacional de Desenvolvimento Científico e Tecnológico (CNPq), pela concessão de bolsa à segunda autora.

\section{Referências}

ALLCHIN, D. Pseudohistory and pseudoscience. Science \& Education, Dordrecht, v. 13, n. 3, p. 179-195, 2004.

ASSIS, A. K. T.; NEVES, M. C. D.; SOARES, D. S. L. Hubble's cosmology: from a finite expanding universe to a static endless universe. In: POTTER, F. $2^{\text {nd }}$ Crisis in Cosmology Conference, CCC-2: proceedings of a conference held at Port Angeles, Washington, USA, 7-11 September 2008. San Francisco: Astronomical Society of the Pacific, 2009. p. 255-267. (Astronomical Society of the Pacific conference series, v. 413).

BARDIN, L. Análise de conteúdo. Lisboa: Edições 70, 2011.

BRITO, A. E. Sobre a formação e a prática pedagógica: o saber, o saber-ser e o saber-fazer no exercício profissional. Linguagens, Educação e Sociedade, Teresina, n. 12, p. 45-50, jan/jun. 2005.

CANGUILHEM, G. Dialectique et philosophie du non chez Gaston Bachelard. In:

Études d'histoire et de philosophie des sciences: concernant les vivants et la vie. 2 . ed. Paris: Librairie Philosophique J. Vrin, 2002. p. 196-207.

CHEVALLARD, Y. La transposition didactique. Paris: La Pensée Sauvage, 1991.

CHRISTIE, J. R. R. The development of the historiography of science. In: OLBY, R. C. et al. (Ed.). Companion to the history of modern science. London: Routledge, 1990. p. 5-22. 
CONCANNON, J. P.; BROWN. P. L.; BROWN, E. Prospective teachers' perceptions of science theories: an action research study. Creative Education, Irvine, v. 4, n. 1, p. 82-88, 2013.

EL-HANI, C. N. Notas sobre o ensino de história e filosofia da ciência na educação científica superior. In: SILVA, C. C. (Org.). Estudos de história e filosofia das ciências: subsídios para a aplicação no ensino. São Paulo: Livraria da Física, 2006. p. 3-21.

FORATO, T. C. M. A natureza da ciência como saber escolar: um estudo de caso a partir da história da luz. 2009. Tese (Doutorado em Educação) - Faculdade de Educação, Universidade de São Paulo, São Paulo, 2009. Disponível em: <http://www.teses.usp.br/ teses/disponiveis/48/48134/tde-24092009-130728/>. Acesso em: 19 jan. 2016.

FORATO, T. C. M.; PIETROCOLA, M.; MARTINS, R. A. Historiografia e natureza da ciência na sala de aula. Caderno Brasileiro de Ensino de Física, Florianópolis, v. 28, n. 1, p. 27-59, 2011.

GIL-PÉREZ, D. et al. Para uma imagem não-deformada do trabalho científico. Ciência \& Educação, Bauru, v. 7, n. 2, p. 125-153, 2001. Disponível em: < http://dx.doi.org/10.1590/ S1516-73132001000200001>. Acesso em: 19 jan. 2016.

GUÇÃO, M. F. B. et al. Seleção de fontes históricas para o trabalho em sala de aula: uma análise do "Poema para Galileu" em duas perspectivas diferentes. In: CALDEIRA, A. M. A. (Org.). Ensino de ciências e matemática V: história e filosofia da ciência. São Paulo: Cultura Acadêmica, 2011. p. 249-268.

GUERRA, A.; REIS, J. C.; BRAGA, M. A. History, philosophy and science in a social perspective: a pedagogical project. Science $\boldsymbol{\&}$ Education, Dordrecht, v. 20, n. 1, p. 1485-1503, 2013.

HODSON, D. Teaching and learning about science: language, theories, methods, history, traditions and values. Rotterdam: Sense Publishers, 2009.

HOTTECKE. D.; SILVA. C. Why implementing history and philosophy in school science education is a challenge: an analysis of obstacles. Science \& Education, Dordrecht, v. 20, n. 1, p. 37-50, 2011.

KAUFMAN, A. M.; RODRIGUEZ, M. E. Escola, leitura e produção de textos. Porto Alegre: Artes Medicas, 1995.

KRAGH, H. Ideologia e mitos na história da ciência. In: . Introdução à

historiografia da ciência. Porto: Porto Editora, 2001. p. 119-165.

KRASILCHIK, M. Prática de ensino de biologia. São Paulo: Edusp, 2012.

KUHN, T. S. A estrutura das revoluções científicas. São Paulo: Perspectiva, 2007.

MARTINS, A. F. P. História e filosofia da ciência no ensino: há muitas pedras nesse caminho.

Caderno Brasileiro de Ensino de Física, Florianópolis, v. 24, n. 1, p. 112-131, 2007. 
MARTINS, L. A. P. História da ciência: objetos, métodos e problemas. Ciência $\&$ Educação, Bauru, v. 11, n. 2, p. 305-317, 2005. Disponível em: < http://www.scielo.br/pdf/ ciedu/v11n2/10.pdf>. Acesso em: 19 jan. 2016.

MARTINS, R. A. Charles Darwin e os marrecos: origem comum e herança de caracteres adquiridos. Boletim de História e Filosofia da Biologia, São Paulo, v. 4, n. 3, p. 9-21, 2010.

Ciência versus historiografia: os diferentes níveis discursivos nas obras sobre história da ciência. In: ALFONSO-GOLDFARB, A. M.; BELTRAN, M. H. R. (Org.). Escrevendo a história da ciência: tendências, propostas e discussões historiográficas. São Paulo: Livraria da Física, 2004. p. 115-147.

. Introdução: a história das ciências e seus usos na educação. In: SILVA, C. C. (Org.).

Estudos de história e filosofia das ciências: subsídios para aplicação no ensino. São Paulo: Livraria da Física, 2006. p. xvii-xxx.

MATTHEWS, M. R. História, filosofia e ensino de ciências: a tendência atual de reaproximação. Caderno Brasileiro de Ensino de Física, Florianópolis, v. 12, n. 3, p. 164-214, 1995. Disponível em: <https://periodicos.ufsc.br/index.php/fisica/article/ view/7084/6555>. Acesso em: 19 jan. 2016.

Science teaching: the role of history and philosophy of science. New York: Routledge, 1994.

NARDI, R. A pesquisa em ensino de ciências e matemática no Brasil. Ciência \& Educação, Bauru, v. 21, n. 2, p. i-v, 2015. Disponível em: <http://dx.doi.org/10.1590/1516731320150020001>. Acesso em: 19 jan. 2016.

PEDUZZI, L. O. Q. Sobre a utilização didática da história da ciência. In: PIETROCOLA, M. (Org.). Ensino de física: conteúdo, metodologia e epistemologia numa concepção integradora. Florianópolis: Ed. UFSC, 2001. p. 236-250.

SAITO, F.; DIAS, M. S. Interface entre história da matemática e ensino: uma atividade desenvolvida com base num documento do século XVI. Ciência \& Educação, Bauru, v. 19, n. 1, p. 89-111, 2013. Disponível em: <http://dx.doi.org/10.1590/S151673132013000100007>. Acesso em: 19 jan. 2016.

SALOMON, G. It is not just the tool, but also the educational rationale that counts. In: EdMedia WORLD CONFERENCE ON EDUCATIONAL MEDIA \& TECHNOLOGY, 2000, Montreal. Keynote talk. Disponível em: <http://www.aace.org/conf/edmedia/00/ salomonkeynote.htm>. Acesso em: 19 jan. 2016.

TARDIF. M. Saberes docentes e formação profissional. Petrópolis: Vozes, 2002.

Saberes profissionais dos professores e conhecimentos universitários: elementos para uma epistemologia da prática profissional dos professores e suas consequências em relação à formação para o magistério. Revista Brasileira de Educação, São Paulo, n. 13, p. 5-24, 2000. Disponível em: < http://educa.fcc.org.br/pdf/rbedu/n13/n13a02.pdf>. Acesso em: 19 jan. 2016. 
WHITAKER, M. A. B. History and quasi-history in physics education: part I. Physics Education, Bristol, v. 14, n. 2, p. 10-112, 1979a.

History and quasi-history in physics education: part II. Physics Education, Bristol, v. 14, n. 3, p. 239-242, 1979 b.

Anexo A. Dissertações analisadas

D1 SILVA, B. V. C. Controvérsias sobre a natureza da luz: uma aplicação didática. 2010. $182 \mathrm{f}$. Dissertação (Mestrado Profissional em Ensino de Ciências Naturais e Matemática) - Universidade Federal do Rio Grande do Norte, Natal, 2010. Disponível em: <http://repositorio.ufrn.br/jspui/ handle/123456789/16055>. Acesso em: 02 mar. 2016.

D2 LOURENÇO, M. T. A inserção da disciplina filosofia no ensino médio e ensino de física. 2010. 127 f. Dissertação (Mestrado Profissional em Ensino de Ciências e Matemática) - Centro de Ciências e Tecnologias, Universidade Estadual da Paraíba, João Pessoa, 2010. Disponível em: <http://tede.bc.uepb.edu.br/jspui/handle/tede/1647>. Acesso em: 02 mar. 2016.

D3 MENEZES, A. M. S. Teoria da relatividade geral no ensino médio: linhas retas e curvas no caminho da física, da literatura e da história e filosofia da ciência. 2010. 99 f. Dissertação (Mestrado Profissional em Ensino de Ciências e Matemática) - Centro Federal de Educação Tecnológica Celso Suckow da Fonseca, Rio de Janeiro, 2010. Disponível em: <http://dippg.cefet-rj.br/index. php?option=com_docman\&task=doc_details\&gid=841\&Itemid=168>. Acesso em: 04 mar. 2016.

D4 MONTEIRO, F. A. Discutindo a ciência através dos episódios históricos: o caso dos raios-X e da radioatividade. 2011. 97 f. Dissertação (Mestrado Profissional em Ensino de Ciências e Matemática) - Centro de Ciências e Tecnologias, Universidade Estadual da Paraíba, João Pessoa, 2011. Disponível em: <http://tede.bc.uepb.edu.br/jspui/handle/tede/1699>. Acesso em: 04 mar. 2016.

D5 MORAIS, A. V. O conceito de energia através da história: a HFC como caminho para inserir física moderna no ensino médio. 2011. Dissertação (Mestrado Profissional em Ensino de Ciências e Matemática) - Centro Federal de Educação Tecnológica Celso Suckow da Fonseca, Rio de Janeiro, 2011. Disponível em: <http://dippg.cefet-rj.br/index.php?option=com_docman\&task=doc_ details\&gid=847\&Itemid=167>. Acesso em: 04 mar. 2016 . 
Anexo A. continuação

D6 ALCANTARA, M. C. História da ciência, filosofia e arte na Holanda do século XVII: construindo um módulo para o ensino dos instrumentos óticos. 2011. 66 f. Dissertação (Mestrado Profissional em Ensino de Ciências e Matemática) - Centro Federal de Educação Tecnológica Celso Suckow da Fonseca, Rio de Janeiro, 2011. Disponível em: < http://dippg.cefet-rj.br/index. php?option $=$ com_docman\&Itemid $=167 \&$ limitstart $=30>$. Acesso em: 04 mar. 2016.

D7 PEREIRA, J. L. Controvérsia entre o modelo corpuscular e ondulatório da luz: um caminho para o ensino de Óptica no Ensino Médio. 2011. Dissertação (Mestrado Profissional em Ensino de Ciências e Matemática) - Centro Federal de Educação Tecnológica Celso Suckow da Fonseca, Rio de Janeiro, 2011. Disponível em: < http:/ / dippg.cefet-rj.br/index.php?option=com_ docman\&Itemid=167\&limitstart=20 > . Acesso em: 04 mar. 2016.

D8 ARCANJO FILHO, M. Demanda epistemológica no ensino de física. 2011. 93 f. Dissertação (Mestrado em Ensino de Ciências e Matemática) - Centro Federal de Educação Tecnológica Celso Suckow da Fonseca, Rio de Janeiro, 2011. Disponível em: < http://dippg.cefet-rj.br/index. php?option $=$ com_docman\&Itemid $=167 \&$ limitstart $=20>$. Acesso em: 04 mar. 2016.

D9 BEZERRA, K. M. Resgatando a dimensão filosófica da física através de um texto paradidático. 2011. 94 f. Dissertação (Mestrado em Ensino de Ciências e Matemática) - Centro Federal de Educação Tecnológica Celso Suckow da Fonseca, Rio de Janeiro, 2011. Disponível em: $<$ http:/ $/$ dippg.cefet-rj.br/index.php?option $=$ com_docman\&Itemid $=167 \&$ limitstart $=50>$. Acesso em: 04 mar. 2016.

D10 GUTTMANN, G. A. M. Investigações das concepções de alunos sobre a dualidade infinitude X finitude na ciência: cosmologia. 2011. 81 f. Dissertação (Mestrado em Ensino de Ciências e Matemática) - Centro Federal de Educação Tecnológica Celso Suckow da Fonseca, Rio de Janeiro, 2011. Disponível em: < http://dippg.cefet-rj.br/index.php?option=com_ docman\&Itemid=167\&limitstart $=40>$. Acesso em: 04 mar. 2016. 